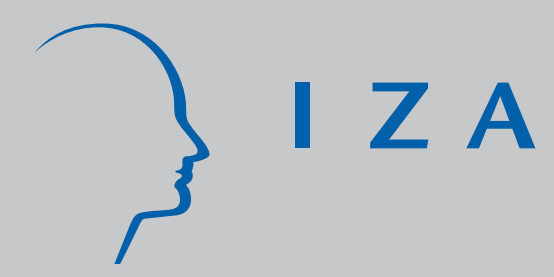

IZA DP No. 2365

Active Labor Market Policy Effects for Women in Europe: A Survey

Annette Bergemann

Gerard J . van den Berg

October 2006 


\title{
Active Labor Market Policy Effects for Women in Europe: A Survey
}

\author{
Annette Bergemann \\ Free University Amsterdam, \\ IFAU Uppsala and IZA Bonn \\ Gerard J. van den Berg \\ Free University Amsterdam, Princeton University, \\ IFAU Uppsala, CEPR, IFS and IZA Bonn
}

\section{Discussion Paper No. 2365 \\ October 2006}

\author{
IZA \\ P.O. Box 7240 \\ 53072 Bonn \\ Germany \\ Phone: +49-228-3894-0 \\ Fax: +49-228-3894-180 \\ E-mail: iza@iza.org
}

\begin{abstract}
Any opinions expressed here are those of the author(s) and not those of the institute. Research disseminated by IZA may include views on policy, but the institute itself takes no institutional policy positions.

The Institute for the Study of Labor (IZA) in Bonn is a local and virtual international research center and a place of communication between science, politics and business. IZA is an independent nonprofit company supported by Deutsche Post World Net. The center is associated with the University of Bonn and offers a stimulating research environment through its research networks, research support, and visitors and doctoral programs. IZA engages in (i) original and internationally competitive research in all fields of labor economics, (ii) development of policy concepts, and (iii) dissemination of research results and concepts to the interested public.
\end{abstract}

IZA Discussion Papers often represent preliminary work and are circulated to encourage discussion. Citation of such a paper should account for its provisional character. A revised version may be available directly from the author. 
IZA Discussion Paper No. 2365

October 2006

\section{ABSTRACT \\ Active Labor Market Policy Effects for Women in Europe: A Survey}

We survey the recent literature on the effects of active labor market policies on individual labor market outcomes like employment and income, for adult female individuals without work in European countries. We consider skill-training programs, monitoring and sanctions, job search assistance, and employment subsidies. The results are remarkably uniform across studies. We relate the results to the relevant level of female labor force participation.

JEL Classification: J08, J22, J16, J64, J68, J78

Keywords: job search, female labor supply, wages, unemployment, schooling, training, monitoring, participation

Corresponding author:

Gerard J. van den Berg

Department of Economics

Free University of Amsterdam

De Boelelaan 1105

1081 HV Amsterdam

The Netherlands

E-mail: gjvdberg@xs4all.nl

\footnotetext{
* The work in this paper is part of the ESRC and IFAU Research Projects "Advancing Programme Evaluation Methods". The financial support by a Marie Curie Fellowship under FP6 of the European Community Program "Structuring the European Research Area" contract number MEIF-CT-2003505916 is acknowledged.
} 


\section{Introduction}

During the past decades, female labor force participation has risen in most European countries. Nevertheless, there are still substantial differences in participation across countries. Moreover, women are typically over-represented among the unemployed. Because of this, active labor market polices are potentially very important to bring women into employment, and to increase their income levels. Such policies are not specifically designed for women, and many evaluation studies do not address the issue to what extent the effects for women differ from the effects for men.

In this paper we survey the existing literature on the effects of active labor market policies on female individual labor market outcomes like employment and income. We consider training programs, monitoring and sanctions, job search assistance, adult education, and employment subsidies. We focus on European countries. High labor market frictions and labor market inflexibility have led to relatively high average unemployment durations and low wage and income inequality. Accordingly, we use a dynamic job search framework to interpret the results.

Since a number of years, the EU itself has been concerned about female labor market outcomes. In 1997 the EU laid down its so-called "European Employment Strategy". This set of policy objectives and guidelines is focused on increasing the employability of individuals, and explicitly emphasizes the aim of obtaining equal opportunity for women and men. Since 1999, gender mainstreaming has been put into concrete terms in the Employment Guidelines of the EU (see Müller and Kurtz 2003). These guidelines emphasize the importance of the reconciliation of work and family life and the return to employment after family-related career breaks. They also contain the directive to document gender-specific effects when evaluating labor market policy programs.

To increase the focus of the survey, we restrict attention to adult women, meaning women aged over 25. Younger individuals often face different sets of labor market policies, notably due to the so-called "comprehensive approach" imposed by the EU. We also exclude active labor market policies for working individuals.

In terms of the individual labor market outcomes, we take the pragmatic approach that we focus on the outcomes that have been deemed interesting (i.e. evaluated) in the literature. Most studies examine the probability of employment 
or its determinants like the duration of unemployment or the transition rate from unemployment to work. Only very few studies (also) examine annual income or wages. Different parameters or outcome measures are informative on different aspects of labor market behavior and policy effectiveness. For example, to understand the behavioral effect it is more interesting to know the effect on the transition rate from unemployment to work than to know the effect on the mean duration of unemployment, because the latter also depends on the moment of treatment exposure and on the presence of other active labor market policies. Moreover, unemployment can end in a transition to non-participation, which has different welfare implications than a transition into work. On the other hand, effects on the mean unemployment duration are important from a cost-benefit point of view, in particular for the institution paying unemployment benefits. Effects on the mean duration are also amenable to incorporate the costs due to the "lock-in" time spent in a program.

We mostly restrict attention to recent studies, meaning $(i)$ studies published since the period covered by the major survey in Heckman, LaLonde and Smith (1999), and (ii) unpublished studies based on data from after that period. This is not a major restriction as not many academic studies with European data have been published before the late 1990s, and those who have generally do not distinguish between gender effects.

We only consider studies that use data at the individual level. These can be survey data and/or register data. Apart from this, different studies use different methodologies. Some use propensity score matching, others use panel data methods, (conditional) difference-in-differences, instrumental variables, social experiments, or timing-of-event (duration analysis) methods. We are agnostic to the methods used in the studies we survey. In general we put most emphasis on studies published in the academic sphere, including academic working paper series. Of course, different methods are sometimes not mutually compatible, or they provide information on different parameters of interest (see e.g. Heckman and Vytlacil, 2005, for a recent overview). We should also make the obvious point that programs are sometimes difficult to compare across countries and over time. Moreover, the boundary between different sets of programs is sometimes difficult to draw. Training programs sometimes include job search assistance, and monitoring may entail enrollment into training.

Some important surveys of active labor market policy effects have been published in the academic literature. We already mentioned the the major survey in 
Heckman, LaLonde and Smith (1999). Surveys with a focus on Europe include Kluve (2006). These surveys do not pay particular attention to effects for women. Fay (1996), Heckman, LaLonde and Smith (1999), and Martin and Grubb (2001) focus on OECD countries, but their conclusions regarding gender differences are mostly driven by studies based on U.S. data.

The outline of the paper is as follows. In Section 2 we discuss economic lines of reasoning that can be used to understand the policy effects at the individual level. We also provide some aggregate statistics on women in the labor market. Section 3 surveys the results. Section 4 concludes and outlines some avenues for future research.

\section{The labor market context}

There is a large literature on the estimation of the effects of changes in the hourly wage on labor supply outcomes, notably participation and number of hours worked. Such analyses are closely linked to neo-classical labor market theory. In the context of continental-European labor market conditions, the results can be interpreted as capturing long-run effects, whereas short-run and medium-run effects are more affected by labor market frictions and involuntary unemployment (see Cahuc and Zylberberg, 2004). Nevertheless, this literature has drawn some conclusions that may be relevant for our purposes. Most importantly, female labor supply is much more responsive to wage changes than male labor supply. This applies to the hours decision for participants but even more so to the participation decision (see e.g. the overview in Killingsworth and Heckman, 1986, and the more recent meta-study by Evers, De Mooij and Van Vuuren, 2006). Secondly, the responsiveness of female labor supply seems to have decreased during the past decades, along with an increase in female labor force participation.

The result that female labor supply is more responsive has been explained by reference to the so-called Le Chatelier principle which basically states that individuals with more options have more elastic supply functions. Suppose that women have more alternatives to devote their time to (notably, in addition to work and leisure, also home work including child care) than men. If the wage rate increases then women substitute time away from both leisure and home work, resulting in a larger labor supply response than for men. Along these lines one can also explain the lower level of labor force participation among women. 
Killingsworth and Heckman (1986) provide a formal analysis and discussion.

This line of reasoning can also be relevant in the context of active labor market programs for unemployed women in a labor market with search frictions. The dynamic decision problem faced by an unemployed woman takes into account that there is an outside option of choosing to bear children and/or become a housewife, while a partner may provide household income. These factors may increase the attractiveness of not working vis-à-vis working. Not willing to work does not necessarily mean that the individual is not registered as unemployed. One may be registered but set a reservation wage higher than the going wage, or have a zero search intensity. Participation in a program that increases labor market opportunities, like a successful skill-enhancing training program, may subsequently lead to job offers that are acceptable and/or to a positive optimal job search intensity. In the long run this would lead to employment. In such cases, one may expect average program effects to be larger for women than for men. Of course, if the program is completely ineffective then the effects should be zero for both genders.

If the female labor force participation is low then these issues may be more relevant. First of all, a low participation goes along with a high sensitivity of female labor supply with respect to the wage. Secondly, the more qualified and potentially productive the adult female population is, the closer actual labor market conditions will be to the conditions that induce an eventual transition into work for many women. In Europe, historically, the average education level of non-participating women in economies with low female labor force participation was not particularly low, so that the potential for their productive participation was relatively high.

A high female labor force participation goes along with lower sensitivity of female labor supply. Moreover, in such a situation, women who are non-participant or long-term unemployed may have on average lower skills than those in the situation of the previous paragraph. Therefore one would expect lower policy effects than in that situation.

A different reason for why active labor market policies could work better for women than for men builds on the assumption that many women have a greater distance to the labor market. Because of this they may under-estimate their opportunities, and they may be unaware of the non-pecuniary utility of being employed. Program participation may then help to increase the eagerness to become employed. This explanation may also be more relevant in economies 
with a relatively low female labor force participation.

Similarly, with a high distance, employers may statistically discriminate against women. Active labor market policies may then provide an opportunity for employers to learn the individual productivity of a woman. This may be particularly relevant for employment subsidies.

Monitoring (i.e., controlling whether unemployed individuals comply with rules on job search effort and behavior) is different from the other policies in that it necessarily reduces the individual's expected present value (see e.g. Van den Berg and Van der Klaauw, 2006). An increase in monitoring is supposed to increase the transition rate to work. However, in that case, the average wage of the jobs will be lower. The line of reasoning earlier in this subsection leads one to suspect that for women it may also be attractive to respond to increased monitoring by way of leaving the labor force.

In Table 1 and 2 we provide descriptive statistics on the labor force participation rates for men and women in different countries and years. We also distinguish between participation in numbers of individuals on the one hand, and participation in terms of part-time versus full-time jobs on the other. In the sequel, we say that an economy has low female labor force participation if the gender participation gap exceeds 10 percentage points in absolute value in the year in Table 2 closest to the years in which we observe the economy under consideration.

\section{$3 \quad$ Policy effects}

\subsection{Skill training}

Here, we summarize the results of 15 studies that distinguish between training effects for women and men. ${ }^{1}$ The range of training courses that are evaluated is broad, but typically the courses take place in classrooms and contain some on-thejob training aspects. Also, the program participation duration typically ranges from 0.5 to 1 year, although there are programs as short as 1 month and as long as

\footnotetext{
${ }^{1}$ See Bergemann, Fitzenberger and Speckesser (2005), Biewen et al. (2006), Bolvig, Jensen and Rosholm (2003), Cavaco, Fougère and Pouget, (2005), Gerfin and Lechner (2002), Kluve, Lehmann and Schmidt (1999), Lalive, Van Ours and Zweimueller (2000), Lechner, Miquel and Wunsch (2004), Lechner, Miquel and Wunsch (2008), Lubyova and Van Ours (1999), Raaum, Torp and Zhang (2002a, 2002b), Richardson and Van den Berg (2006), Weber and Hofer (2004), and Zhang (2003).
} 
Table 1: Selected labor market indicators for prime-aged women

\begin{tabular}{r|ccc|ccc|ccc}
\hline \hline & \multicolumn{3}{|c|}{ Labor force } & \multicolumn{3}{c|}{ Part-time } & \multicolumn{3}{c}{ Unemployment } \\
& participation rate & \multicolumn{3}{c|}{ share } & \multicolumn{3}{c}{ rate } \\
\hline & 1984 & 1994 & 2004 & 1984 & 1994 & 2004 & 1984 & 1994 & 2004 \\
\hline Austria & & 71.7 & 79.6 & & & 29.6 & & 3.8 & 4.8 \\
Belgium & 56.4 & 67.2 & 74.3 & 24.1 & 30.0 & 34.1 & 15.7 & 11.2 & 7.4 \\
Czech Republic & & 83.2 & 80.9 & & 5.6 & 5.2 & & 4.4 & 9.3 \\
Denmark & 82.7 & 82.7 & 84.9 & 36.7 & 26.2 & 24.3 & 9.0 & 9.0 & 5.1 \\
Finland & 85.8 & 84.0 & 84.6 & & 11.5 & 14.9 & 3.6 & 12.5 & 7.6 \\
France & 68.2 & 76.7 & 80.3 & 21.4 & 24.5 & 23.6 & 8.7 & 13.1 & 10.0 \\
Germany & 58.0 & 72.6 & 82.0 & 25.8 & 28.0 & 37.0 & 7.2 & 10.1 & 9.0 \\
Western Germany & & 68.0 & 79.0 & & 43.0 & 53.0 & & 7.0 & 9.0 \\
Eastern Germany & & 94.0 & 92.0 & & 18.0 & 35.0 & & 21.0 & 20.0 \\
Ireland & 32.1 & 53.6 & 67.9 & 17.6 & 25.5 & 35.1 & 8.2 & 13.4 & 3.1 \\
Netherlands & 43.4 & 64.5 & 76.7 & & 54.5 & 60.2 & 9.0 & 7.8 & 3.6 \\
Norway & 74.2 & 79.4 & 82.8 & & 37.7 & 33.2 & 2.5 & 3.8 & 3.3 \\
Poland & & 78.6 & 76.4 & & & 17.5 & & 14.5 & 18.0 \\
Spain & 34.1 & 54.6 & 68.3 & & 14.3 & 17.2 & 14.0 & 28.6 & 13.8 \\
Sweden & 88.2 & 86.9 & 85.3 & & 24.9 & 20.8 & 2.3 & 6.8 & 5.2 \\
Switzerland & & 74.0 & 80.8 & & 44.9 & 45.3 & & 4.2 & 4.6 \\
Slovak Republic & & 81.1 & 84.0 & & 4.4 & 4.5 & & 11.6 & 17.5 \\
\hline \hline Europe & 57.2 & 66.0 & 69.6 & 26.9 & 27.0 & 28.2 & 8.9 & 10.9 & 9.2 \\
\hline \hline
\end{tabular}

Notes: Part-time share is calculated with respect to all employed individuals. Labor force participation rate and unemployment rate for Netherlands is not available for 2004, 2003 data is used instead. Data for the two different parts of Germany refer to individuals aged between 35 and 55 years and is taken from Datenreport Deutschland 2006, otherwise OECD Online Statistic Database 2006. 
Table 2: Male-Female gap in selected labor market indicators for prime-aged individuals

\begin{tabular}{r|ccc|ccc|ccc}
\hline \hline & \multicolumn{3}{|c|}{ Labor force } & \multicolumn{3}{c|}{ Part-time } & \multicolumn{3}{c}{ Unemployment } \\
& participation rate & \multicolumn{3}{c}{ share } & \multicolumn{3}{c}{ rate } \\
\hline & 1984 & 1994 & 2004 & 1984 & 1994 & 2004 & 1984 & 1994 & 2004 \\
\hline Austria & & 20.8 & 13.3 & & & -25.8 & & -0.8 & -1.0 \\
Belgium & 37.7 & 24.9 & 16.8 & -20.4 & -25.5 & -27.8 & -9.6 & -4.7 & -1.4 \\
Czech Republic & & 12.0 & 13.7 & & -3.6 & -3.7 & & -1.8 & -3.7 \\
Denmark & 10.3 & 9.2 & 6.4 & -28.5 & -16.5 & -12.7 & -1.8 & -2.3 & -0.7 \\
Finland & 7.6 & 6.2 & 5.4 & & -5.0 & -7.0 & 0.4 & 3.0 & -0.7 \\
France & 27.7 & 18.4 & 13.4 & -17.4 & -19.2 & -18.8 & -3.3 & -3.5 & -2.4 \\
Germany & 35.6 & 20.3 & 11.3 & -24.0 & -25.0 & -30.7 & -1.5 & -3.6 & 0.8 \\
Western Germany & & 28.0 & 18.0 & & -42.0 & -49.0 & & -1.0 & -1.0 \\
Eastern Germany & & 3.0 & 5.0 & & -18.0 & -30.0 & & -7.0 & -2.0 \\
Ireland & 63.6 & 37.7 & 23.8 & -13.9 & -19.1 & -28.2 & 7.3 & 0.0 & 1.4 \\
Netherlands & 48.5 & 27.8 & 16.7 & & -43.2 & -45.1 & 3.2 & -2.6 & -0.1 \\
Norway & 22.3 & 11.1 & 7.3 & & -30.0 & -22.9 & 0.2 & 1.3 & 1.0 \\
Poland & & 12.3 & 11.6 & & & -10.0 & & -3.2 & -2.0 \\
Spain & 60.5 & 38.5 & 24.2 & & -12.0 & -14.6 & 0.0 & -12.3 & -6.9 \\
Sweden & 6.7 & 4.4 & 4.8 & & -17.7 & -12.3 & -0.1 & 2.6 & 0.4 \\
Switzerland & & 23.4 & 14.9 & -38.1 & -37.2 & & -1.1 & -1.1 \\
Slovak Republic & & 13.8 & 9.7 & & -3.1 & -3.2 & & -1.2 & -2.9 \\
\hline \hline & 28.6 & 18.9 & 14.1 & -37.1 & -34.2 & -30.4 & -0.4 & 3.4 & 0.4 \\
\hline Europe & 37.5 & 26.8 & 21.9 & -23.4 & -22.1 & -22.1 & -2.0 & -2.7 & -1.6 \\
\hline
\end{tabular}

Notes: Part-time share is calculated with respect to all employed individuals. The labor force participation rate and unemployment rate for Netherlands are unavailable for 2004; 2003 data are used instead. Data for the two different parts of Germany refer to individuals aged between 35 and 55 years and are taken from Datenreport Deutschland 2006; otherwise OECD Online Statistic Database 2006. 
3 years. Short courses are supposed to upgrade existing skill knowledge, whereas long courses are supposed to lead to the acquisition of skills for a completely new occupation. Occasionally, courses take place in practice firms or in the context of a regular job.

The majority of studies (13 out of 15) find positive effects of training on labor market outcomes for women, for all types of training and/or averaged over all training types considered, or (in 3 cases) for selected types of training. Most of the studies focus on the employment probability or the transition rate to work as the outcome of interest. In many cases the effects on such employment outcomes exceed the effects for men, and often the latter are close to zero and insignificant. ${ }^{2}$ Studies reaching these conclusions evaluate training programs in e.g. Austria in 1999-2001, France in 1996-1997, Western Germany in 1993-1994 and 2000-2002, Norway in 1990-2000, or Poland in 1992-1994. As a comparison with Table 1 and Table 2 reveals, the female labor force participation was relatively low in these areas at the time of the program. The gap in labor force participation for example for France in 1994 was 18.6 percentage points. For Western Germany the gap in 2004 still reached 18 percentage points, declining from as high as 28 percentage points in 1994. In countries like Poland and Norway the gap amounted to about 11 percentage points in 1994.

In contrast, Eastern Germany, Denmark and Sweden enjoy a relative high female labor market participation. In these areas the gap between male and female labor force participation rate amounts to less than 10 percentage points in absolute value (see Table 2). Evaluation studies for training programs in these areas typically come to the conclusion that there are no gender specific effects of training. ${ }^{3}$

Thus, positive and larger effects of training on employment outcomes for women compared to men go along with a larger gender gap in labor force partici-

\footnotetext{
${ }^{2}$ E.g. Biewen et al. (2006), Cavaco, Fougère and Pouget (2005), Kluve, Lehmann and Schmidt (1999), Lalive, Van Ours and Zweimueller (2000), Lechner, Miquel and Wunsch (2004), Weber and Hofer (2004), and Zhang (2003).

${ }^{3}$ See for example Bergemann, Fitzenberger and Speckesser (2005), Biewen et al. (2006), Bolvig, Jensen, Rosholm (2003), and Richardson and Van den Berg (2006). Lechner, Miquel and Wunsch (2004) find that some programs work better for women and some programs work better for men, but this does not necessarily violate our hypothesis, as they argue that different effects are connected with the men and women following different programs. Men were often trained in construction work and construction workers suffer since the mid 1990s from an extremely high unemployment rate.
} 
pation. This is in agreement to the economic line of reasoning in Section 2, which emphasizes the importance of a shift away from home production in response to a productivity increase due to training. ${ }^{4}$

It is not possible to address the question whether training programs raise the earnings or wages of women and whether these effects are larger than for men, simply because too few studies investigate this issue by gender. ${ }^{5,6}$

\subsection{Job search assistance}

Job search assistance typically encompasses a variety of activities aimed at improving the speed of finding a suitable job. Notably, it includes an assessment of the individual's skills, counseling, teaching presentation and job search abilities, as well as direct referral of unemployed to job openings. The activities can take place in one-to-one meetings with case workers or in job clubs, or as classroom training. The boundary between job search assistance and skill training programs is somewhat fluid, as job search assistance may also involve short training courses to upgrade certain skills. For example, a course on how to use the internet to search for jobs also enables the individual to use the internet in general.

In general, for each gender, evaluation studies find favorable effects of job search assistance on the various employment outcome measures of interest, like the exit rate to work, the job retention rate, the employment probability, and the

\footnotetext{
${ }^{4}$ Two studies deviate from this pattern. Switzerland has a low female labor force participation, but Gerfin and Lechner (2002) find no major differences between short run effects of training for men and women at the end of the 1990s. The employment probability effects are generally negligible or even negative. It should be mentioned that Lalive, Van Ours and Zweimüller (2000), who cover the same time period for Switzerland, find that there are generally positive effects for women, and larger effects than for men. The second exception is Lubyova and Van Ours (1999) who estimate positive effects of training for men and women in Slovakia, but the effects for men are larger than for women. However, a model specification test casts doubt on the validity of the specification.

${ }^{5}$ Raaum, Torp and Zhang (2002a, 2002b), and Lechner, Miquel and Wunsch (2008).

${ }^{6}$ Adult education programs are similar to skill training programs in that they aim to enhance productivity and employability. We do not cover their evaluation because, first of all, adult education is generally not regarded to be an active labor market policy, its participants often being categorized as non-labor-force-participants, and secondly, there are almost no evaluation studies by gender. Using recent Swedish data, Albrecht, Van den Berg and Vroman (2004) find a slightly stronger employment effect for men, but the sample sizes are too small to put significance to this finding.
} 
probability of not receiving benefits. ${ }^{7}$ All seven studies examine economies with a relatively low female labor force participation. Of these, 5 (whereby one for a subprogram) find larger effects for women than for men. ${ }^{8}$ However, some studies find similar effects for men and women, or less positive effects for women than for men, even though they also concern economies with a low female labor force participation. ${ }^{9}$ One of the studies also evaluates job search assistance programs in a setting with relatively high female labor force participation. ${ }^{10}$ This study finds no effects on the employment probability for women but small positive effects for men.

\subsection{Monitoring and sanctions}

In European countries, monitoring the job search effort of unemployed workers, and punishing them financially if they do not meet the effort requirements, has become increasingly common (see e.g. OECD, 2000, for a survey). The monitoring may be purely administrative. For example, the case worker may double-check whether the unemployed individual has made the applications that she states to have made in the submitted monthly overview of job search activities. However, monitoring also often involves regular meetings at the UI agency or the employment office, at which recent search activities are evaluated and a plan for the next period is made. This may even include a directive to accept a particular open vacancy. Usually the agencies only consider samples of cases. If the individual is detected not to comply with the guidelines then she may be punished with a sanction in the form of a benefits reduction which is often combined with an increased monitoring rate and the threat of a more severe punishment in case of repeat offense. A typical unemployment-benefits reduction amounts to $15 \%$ of the benefits level for a period of 2 months.

\footnotetext{
${ }^{7}$ See Biewen et al. (2006), Crépon, Dejemeppe and Gurgand (2005), Fougère, Pradel and Roger (2005), Hujer, Thomsen and Zeiss (2006), Lalive, Van Ours and Zweimüller (2000), and Weber and Hofer (2004). The only study reporting significantly negative effects, and this for both genders, is Gerfin and Lechner (2002).

${ }^{8}$ Compare Biewen et al. (2006), Crépon, Dejemeppe and Gurgand (2005), Fougère, Pradel and Roger (2005), Lalive, Van Ours and Zweimüller (2000), and Weber and Hofer (2004). These 5 studies concern Austria in 2000, France in the mid 1990s and beginning 2000s, Western Germany in the mid 2000s and Switzerland in the mid 1990s (see Table 1 and Table 2).

${ }^{9}$ Crépon, Dejemeppe and Gurgand (2005), Hujer, Thomson and Zeiss (2006), and Gerfin and Lechner (2002).

${ }^{10}$ Eastern Germany, in Biewen et al. (2006).
} 
All studies discussed in this subsection concern economies with a relatively low female labor force participation. Three studies estimate gender-specific monitoring effects. ${ }^{11}$ Their primary outcome measure is the exit rate out of unemployment. One of these studies finds significant positive effects of monitoring on the exit rate out of unemployment for both genders. One study finds a significant positive effect for men but an insignificant positive effect for women, and the third study does not find significant effects for either gender, but its sample size is small. The studies also examine the destination state following exit out of unemployment, i.e. they consider exit to work and exit to non-participation as possible outcomes. The two studies that found significant effects on the total exit rate also show that the positive effect on exit to work is larger for men than for women, whereas the positive effect on exit to non-participation is larger for women that for men. This confirms the hypothesis formulated in Section 2.

We now turn to studies on the effects of imposition of a sanction. Two studies estimate gender-specific sanction effects. ${ }^{12}$ Both take the transition rate from unemployment to employment as the outcome measure (exits to other destinations are virtually absent in their data). They find that upon imposition of a sanction, the transition rate jumps to a significantly higher level, for men as well as women. One study finds larger effect for women, whereas the other finds similar effects for men as for single mothers. The order of magnitude of the effect is often such that the transition rate doubles. Such effects are substantial, and they indicate that the individuals are responsive to monetary incentives. To put this differently, the re-employment rate can be increased among individuals who are at risk of a sanction if one tightens the monitoring or the search effort conditions for benefits entitlement. The effect does not vanish after benefits are restored to their previous level, so presumably the threat of severe additional sanctions plays a major role in the magnitude of the effect. Indeed, recidivism seems to be rare.

\subsection{Employment subsidies}

Employment subsidies arguably constitute the most heterogeneous group of policies. They encompass (i) direct job creation schemes in the public and non-profit sectors, (ii) hiring subsidies for private-sector employers if they hire an unem-

\footnotetext{
${ }^{11}$ Dolton and O'Neill (2002), Van den Berg and Van der Klaauw (2006), and McVicar (2006).

${ }^{12}$ Van den Berg, Van der Klaauw and Van Ours (2004) and Abbring, Van den Berg and Van Ours (2005).
} 
ployed worker, and (iii) start-up grants for unemployed individuals who set up their own business. Typically these measures are temporary, in contrast to employment tax credits for which in general no time limits are imposed (for a comparison, see for example Blundell and Meghir, 2001). Job creation schemes and hiring subsidies are not necessarily expected to lead to a permanent job with the same employer. The studies we survey mostly focus on the employment probability and the transition rate out of unemployment for women as outcomes of interest.

We first summarize the results from the four studies estimating gender-specific effects of hiring subsidies for private-sector employers. ${ }^{13}$ All of the four studies find positive effects for women. The data are all from economies with a relatively low female labor force participation. The estimated effects for men never exceed those for women. However, in two of the four cases the estimated effect for men is similarly positive. In the two other cases, the estimates for men show a significantly negative impact on their employment chances.

One study considers start-up grants. ${ }^{14}$ This study, with data from Western Germany, finds that grants with a length of 0.5 to 3 years increase the employment probability for men and women. The effect for women is larger.

Finally, we turn to job creation schemes. Let us first review the results for economies with a relatively low female labor force participation. Six studies satisfy this condition. ${ }^{15}$ The results are mixed, and this perhaps reflects the huge amount of heterogeneity of the various job creation programs in terms of the types of jobs created and the guidance. The estimates range from significantly positive with respect to the exit rate to work to significantly negative with respect to the employment probability. There is also no clear pattern in the gender difference: it can be positive, zero, or negative.

Four studies estimate individual employment effects of job creation schemes in Eastern Germany. ${ }^{16}$ These four, together with the one study with Danish data

\footnotetext{
${ }^{13}$ Gerfin and Lechner (2002), Gerfin, Lechner and Steiger (2005), Kluve, Lehmann and Schmidt (1999), and Zhang (2003). Lalive, Van Ours and Zweimüller (2000) and Bolvig, Jensen and Rosholm (2003) do not distinguish between job creation schemes and hiring subsidies. The latter two studies find a positive effect for women and a smaller positive effect for men.

${ }^{14}$ Baumgartner and Caliendo 2006.

${ }^{15}$ Gerfin and Lechner (2002), Gerfin, Lechner and Steiger (2005), Hujer, Caliendo and Thompsen (2004, 2006), Van Ours (2004), and Zhang (2003). See also footnote 13 concerning Lalive, Van Ours and Zweimüller (2000).

${ }^{16}$ Bergemann (2005), Eichler and Lechner (2002), and Hujer, Caliendo and Thompsen (2004,
} 
that merges job creation schemes and hiring subsidies, ${ }^{17}$ represent the only studies of employment subsidy policies in economies with a relatively high labor force participation. All five reach the conclusion that the effects are more favorable for women than for men. The estimated effects for women range from a strong reduction in the unemployment probability to a slight increase in the conditional probability of exiting nonemployment. However, at least part of the reduction in the unemployment probability in Eastern Germany is due to women leaving the labor force. The estimated effects for men do not all have the same sign.

The results for hiring subsidies and start-up subsidies are in line with the results in the rest of the paper. The findings for job creation are somewhat out of line with these. Job creation programs seem to perform uniformly well for women in economies with a high labor force participation, in the sense that they leave unemployment faster, and that they benefit more from the program than men. There are some possible explanations. First, participation in a job creation programs may help to overcome statistical discrimination by employers against individual women. Observation of the woman's performance in a created job may provide an opportunity for employers to learn the individual productivity of a woman. This may be particularly relevant in an economy with a high female labor force participation, because employers may then feel that unemployed women in particular constitute a pool of "bad draws" from the productivity distribution. Secondly, all studies on which this result is based except one concern Eastern Germany, so the result may be a specificity of the Eastern German situation. Indeed, women in East Germany seem to move relatively often to labor-marketnon-participation after participation in a job creation program.

\section{Conclusions}

The results in the empirical literature are remarkably uniform. In general, active labor market policies have a positive effect on employment outcomes for women. Moreover, the effects are larger than for men, in particular in economies with a relatively low female labor force participation. These conclusions are strongest for skill-training programs. Thus, positive and larger effects of training on employment outcomes for women compared to men go along with a larger gender

2006).

${ }^{17}$ Bolvig, Jensen and Rosholm (2003). 
gap in labor force participation. This is in agreement to the economic line of reasoning in Section 2, which emphasizes the importance of a shift away from home production in response to productivity increases due to training. For job search assistance programs, hiring subsidies, and start-up grants, the conclusions are similar. With female labor force participation increasing in a given economy over time, one may expect the effectiveness of these active labor market policies to decrease for women, into the direction of the more limited effectiveness for men. For men, job search assistance programs seem to be more effective than skill-training programs.

Monitoring strongly affects women's exit rate out of unemployment. The size of the effect is more or less equal to that for men, but the exit destination is more often non-participation for women and employment for men. Job creation program participation also sometimes leads to a higher exit into non-participation for women. In the light of the general findings for other programs, job creation programs perform remarkably well for women in economies with a high labor force participation, in the sense that they leave unemployment faster and that they benefit more from the program than men. We conjecture that this is because participation in job creation programs may help to overcome statistical discrimination by employers against individual women.

We finish by pointing out a direction for further research. Evaluation studies are often unable to address over-all welfare effects of program participation. For example, monitoring presumably leads to a lower average productivity of accepted jobs; employment subsidies in the private sector may crowd out other potential workers; and training programs have lock-in effects that may be hard to quantify. Such effects mitigate any positive treatment effects. In general, total program participation costs are difficult to observe as well. These difficulties are of course not restricted to evaluation studies by gender. In general, comprehensive register data on wages, hours, job application procedures, and the functioning of employment offices, may help to overcome some of these problems. What adds to the evaluation problems for women is that the line between being registered as unemployment and being non-participant in the labor market is often thin. This implies that potential program participants may be untraceable in data sets of labor market participants. Moreover, policy effects may have an effect of household members' labor market outcomes. It seems useful to therefore link the evaluation data to registers on family members' outcomes. 


\section{References}

Abbring, J.H., G.J. van den Berg, and J.C. van Ours (2005), "The effect of unemployment insurance sanctions on the transition rate from unemployment to employment", Economic Journal, 115, 602-630.

Albrecht, J.W., G.J. van den Berg, and S.B. Vroman (2004), "The Knowledge Lift: The Swedish adult education program that aimed to eliminate low worker skill levels", Working paper, IFAU, Uppsala.

Baumgartner, H.J. and M. Caliendo (2006), "Turning unemployed into selfemployed: The relative effectiveness of two programmes in West Germany", mimeo, DIW, Berlin.

Bergemann, A. (2005), "Do job creation schemes initiate positive dynamic employment effects? Evidence from East Germany?", mimeo, Free University Amsterdam, Amsterdam.

Bergemann, A., B. Fitzenberger, and S. Speckesser (2005), "Evaluating the dynamic employment effects of training programs in East Germany using conditional difference-in-differences", Working paper, IZA, Bonn.

Biewen, M., B. Fitzenberger, A. Osikominu, and M. Waller (2006), "Employment effects of short and medium term further training programs in Germany in the early 2000s", mimeo, Goethe University Frankfurt, Frankfurt am Main.

Blundell, R. and C. Meghir (2001), "Active labour market policy vs employment tax credits: Lessons from recent UK reforms", Swedish Economic Policy Review, 8, 239-265.

Bolvig, I., P. Jensen, and M. Rosholm (2003), "The employment effects of active social policy", Working paper, Aarhus School of Business, Aarhus.

Cahuc, P. and A. Zylberberg (2004), Labor economics, MIT Press, Cambridge.

Cavaco, S., D. Fougère, and J. Pouget (2005), "Estimating the effect of a retraining program for displaced workers on their transition to permanent jobs", Working paper, IZA, Bonn.

Crépon, B., M. Dejemeppe, and M. Gurgand (2005), "Counseling the unemployed: Does it lower unemployment duration and recurrence?", Working paper, IZA, Bonn. 
Dolton, P. and D. O’Neill (2002), "The long-run effects of unemployment monitoring and work search programmes", Journal of Labor Economics, 20, 381-403.

Eichler, M. and M. Lechner (2002), "An evaluation of public employment programmes in the East German state of Sachsen-Anhalt", Labour Economics, 9, $143-186$.

Evers, M., R.A. de Mooij, and D.J. van Vuuren (2006), "What explains the variation in estimates of labour supply elasticities?", Working paper, Tinbergen Institute, Amsterdam.

Fay, R.G. (1996), "Enhancing the effectiveness of active labour market policies: Evidence from programme evaluations in OECD countries", Working paper, OECD, Paris.

Fougère, D., J. Pradel, and M. Roger (2005), "Does job-search assistance affect search effort and outcomes? A microeconometric analysis of public versus private search methods", Working paper, IZA, Bonn.

Gerfin, M. and M. Lechner (2002), "A microeconometric evaluation of the active labour market policy in Switzerland", Economic Journal, 112, 854-893.

Gerfin, M., M. Lechner, and H. Steiger (2005), "Does subsidised temporary employment get the unemployed back to work? An econometric analysis of two different schemes", Labour Economics, 12, 807-835.

Heckman, J.J., R.J. LaLonde, and J.A. Smith (1999), "The economics and econometrics of active labor market programs", in O. Ashenfelter and D. Card, editors, Handbook of Labor Economics, Volume III, North-Holland, Amsterdam.

Heckman, J.J. and E.J. Vytlacil (2005), "Structural equations, treatment effects and econometric policy evaluation", Econometrica, 73, 669-738.

Hujer, T., M. Caliendo, and S. Thomsen (2004), "New evidence on the effects of job creation schemes in Germany - A matching approach with threefold heterogeneity", Research in Economics, 257-302.

Hujer, T., M. Caliendo, and S. Thomsen (2006), "Identfying effect heterogeneity to improve the efficiency of job creation schemes in germany", Applied Economics, forthcoming.

Hujer, T., S. Thomsen, and C. Zeiss (2006), "The effects of short-term training measures on the individual unemployment duration in West Germany", Working paper, IZA, Mannheim. 
Killingsworth, M.R. and J.J. Heckman (1986), "Female labor supply: A survey", in O. Ashenfelter and R. Layard, editors, Handbook of Labor Economics, North-Holland, Amsterdam.

Kluve, J. (2006), "The effectiveness of European active labor market policy", Working paper, RIW, Essen.

Kluve, J., H. Lehmann, and C.M. Schmidt (1999), “Active labor market policies in Poland: Human capital enhancement, stigmatisation, or benefit churning", Journal of Comparative Economics, 27, 61-89.

Lalive, R., J.C. van Ours, and J. Zweimller (2000), "The impact of active labor market programs on the duration of unemployment", Working paper, IZA, Bonn.

Lechner, M., R. Miquel, and C. Wunsch (2008), "The curse and blessing of training the unemployed in a changing economy: The case of East Germany after unification", German Economic Review, forthcoming.

Lechner, M., T. Miquel, and C. Wunsch (2004), "Long-run effects of public sector sponsored training in West Germany", Working paper, University St. Gallen, SIAW, St. Gallen.

Lubyova, M. and J.C. van Ours (1999), "Effects of active labor market programs on the transition rate from unemployment into regular jobs in the Slovak Republic", Journal of Comparative Economics, 27, 90-112.

Martin, J.P. and D. Grubb (2001), "What works and for whom: a review of OECD countries' experiences with active labour market policies", Swedish Economic Policy Review, 8, 9-56.

McVicar, D. (2006), "Job search monitoring intensity and unemployment exit: Evidence from a jobseeker's allowance natural experiment", Working paper, Queen's University, Belfast.

Müller, P. and B. Kurtz (2003), "Active labour market policy and gender mainstreaming in germany", Working paper, IAB, Nürnberg.

OECD (2000), Employment Outlook 2000, OECD, Paris.

Raaum, O., H. Torp, and T. Zhang (2002), "Business cycles and the impact of labour market programmes", Working paper, University of Oslo, Oslo. 
Raaum, O., H. Torp, and T. Zhang (2002), "Do individual programme effects exceed the costs? Norwegian evidence on long run effects of labour market training", Working paper, University of Oslo, Oslo.

Richardson, K. and G.J. van den Berg (2006), "Swedish labor market training and the duration of unemployment", Working paper, IZA, Bonn.

Van den Berg, G.J. and B. van der Klaauw (2006), "Counseling and monitoring of unemployed workers: Theory and evidence from a controlled social experiment", International Economic Review, 47, forthcoming.

Van den Berg, G.J., B. van der Klaauw, and J.C. van Ours (2004), "Punitive sanctions and the transition rate from welfare to work", Journal of Labor Economics, 22, forthcoming.

Van Ours, J.C. (2004), "The locking-in effect of subsidized jobs", Journal of Comparative Economics, 32, 37-55.

Weber, A. and H. Hofer (2004), "Are job search programs a promising tool? A microeconomic evaluation for Austria", Working paper, IZA, Bonn.

Zhang, T. (2003), "Identifying treamtment effects of active labour market programmes for Norwegian adults", mimeo, University of Oslo, Oslo. 